Meta

Journal des tradlucteurs

Translators' Journal

\title{
Vocabulaire des assurances sociales
}

\section{Jean-Paul de Grandpré}

Volume 12, numéro 1, mars 1967

URI : https://id.erudit.org/iderudit/002496ar

DOI : https://doi.org/10.7202/002496ar

Aller au sommaire du numéro

Éditeur(s)

Les Presses de l'Université de Montréal

ISSN

0026-0452 (imprimé)

1492-1421 (numérique)

Découvrir la revue

Citer ce document

de Grandpré, J.-P. (1967). Vocabulaire des assurances sociales. Meta, 12(1),

16-17. https://doi.org/10.7202/002496ar

Ce document est protégé par la loi sur le droit d'auteur. L'utilisation des services d'Érudit (y compris la reproduction) est assujettie à sa politique d'utilisation que vous pouvez consulter en ligne.

https://apropos.erudit.org/fr/usagers/politique-dutilisation/
Cet article est diffusé et préservé par Érudit.

Érudit est un consortium interuniversitaire sans but lucratif composé de l’Université de Montréal, l'Université Laval et l'Université du Québec à Montréal. Il a pour mission la promotion et la valorisation de la recherche. https://www.erudit.org/fr/ 


\section{Vocabulaire des assurances sociales}

Le deuxième Cahier de l'Office de la langue française ${ }^{1}$ est consacré au vocabulaire des assurances sociales. Ce lexique, qui a été préparé par le Comité d'étu-

1. Ministère des Affaires culturelles du Québec, 1966. 
dè des termes de médecine, sous la direction des docteurs Georges Desrosiers et Jacques Boulay, en collaboration avec l'Office de la langue française, est une bouffée d'air salubre dans, un climat jusqu'ici en proie aux miasmes de l'anglicisme et de l'illogisme en matière de langage.

Les auteurs, affichant une connaissance peu commune de ce secteur de la langue des assurances, nous servent un répertoire de termes remarquables par leur précision et leur frappe. Chaque expression est accompagnée d'une définition. On voit ainsi que le mot rente s'analyse en une somme fixe touchée chaque année sur un capital aliéné par contrat. Voilà qui évitera désormais tout danger de confusion entre ce terme et son cousin, le mot pension.

Ce glossaire regorge d'expressions justes et entièrement normalisées: assurance-décès que, dans les organismes d'assurance sur la vie, on se plaît à appeler «assurance-vie », malgré la fâcheuse contradietion qui existe dans les termes; prestation, garantie et indemnité, qui ont été substitués à «bénéfice », ce trop fameux anglicisme-tandem ; cotisation, délai de carence, entrée en jouissance, prise en charge, titulaire, sinistre, ete., antant d'expressions que l'on semblait ignorer jusqu'ici, et qu'il faut pourtant connaître si l'on veut que nos enfants puissent un jour lire, sans protester ni s'ébahir, des textes techniques rédigés en français.

Au nom des usagers de la langue des assurances sociales et à celui des traducteurs exerçant dans les branches connexes, nous remercions le Comité d'étude des termes de médecine et l'«Office» pour le merveilleux outil qu'ils nous offrent et la cantion qu'ils nous apportent.

Jean-Paul de Grandpré 